\title{
Role of Polarimetric SAR data for discrimination/biophysical parameters of crops based on canopy architecture.
}

\author{
Dipanwita Haldar, Manab Chakraborty, K.R. Manjunath and J.S. Parihar \\ Space Applications Centre, ISRO, Ahmedabad-380015 \\ dipanwita@sac.isro.gov.in, manab@sac.isro.gov.in, krmanjunath@sac.isro.gov.in, jsparihar@ gmail.com
}

KEYWORDS: SAR polarimetry, circular /linear polarization, crop separability, crop biomass, multi-date SAR data, erectophiles, planophiles.

\begin{abstract}
Synthetic Aperture Radar (SAR) sensors have great potential for a wide range of agricultural applications, owing to their capability of all-weather observation. It is particularly useful in tropical regions in Asia where most of the crops are grown in rainy season. The use of SAR images for the assessment of rice-planted area is in operational stage in Asian countries owing to its characteristic temporal signature however, applications of SAR images for the estimation of biophysical plant variables are challenging, especially for crop scattering and discrimination in case of other tropical crops. Canopy geometry and architecture mainly govern the interaction of microwave signal with the vegetation. In this study evaluation of C-band SAR data at different polarization combinations in linear as well as circular polarimetric imaging modes for rabi crops and other associated landuse has been attempted. Also understanding the scattering response of various crops based on canopy architecture was attempted. The scattering parameters were found to vary for planofiles and ere ctophiles, partitioning of scattering and absorption were determined.
\end{abstract}

\section{INTRODUCTION}

Monitoring vegetation properties has received much attention among the several remote sensing applications. Crop condition assessment and yield simulations using Landsat and MODIS were extensively carried out by Doriaswamy et al., 2004. A large amount of experimental activities (Boerner et al., 1987, Chakraborty et al., 2005, Haldar et al., 2012) has been carried out to investigate the sensitivity of microwave sensors to vegetation parameters. In detail, discriminating among the various agricultural species and retrieving biomass are two major application objectives of radar vegetation studies. Backscattering coefficient has been reported to be sensitive to crop biomass (Ulaby et al., 1987). However, biomass effects are strongly dependent on sensor configuration (frequency, polarization, incidence angle) and affected by other parameters, like soil moisture and roughness, plant density, leaf and stem dimensions. Therefore, the sensor configuration has to be properly designed to have biomass effects dominant with respect to the other ones. In order to retrieve biomass, the observed fields must be pre-classified, since the different plant geometries correspond to different biomass sensitivities. Several experimental results (Toan et al., 1987, Wang and Mo., 1990, Freeman, 2007) point out that radar system can discriminate vegetation and specifically agricultural fields from other areas. Moreover, they have classification capabilities especially when multitemporal data are used, covering the cycle of growth for each crop. It follows that the two objectives of classifying and biomass retrieving are related to each other.

Synthetic Aperture Radar (SAR) sensors have great potential for a wide range of agricultural applications, owing to their capability of all-weather observation. Discrimination of crops from other land cover classes and crop classifications are important activities for agricultural monitoring and timely forecasting of crop production in India. In this regard, airborne as well as space-borne remote sensing data particularly Synthetic Aperture Radar (SAR) data has shown promising results in crop monitoring and classification with reasonably high accuracy. While use of SAR backscatter coefficient in different polarizations and frequencies for crop identification and monitoring have been reported (Toan $e t$ al., 1989 \& 1997; Hoekman and Bouman, 1993; Kurosu et al., 1995; Schotten et al., 1995), using polarimetric scattering matrix that contains information about polarization amplitude as well as phase for crop characterization and classification has also been studied (Freeman et al., 1994; Skriver et al., 1999; Lee et al., 2001; Ainsworth et al., 2009; Haldar et al., 2012; Turkar, et al., 2012, Panigrahy et al., 2013). Attempted has also been made to establish relationships between polarization signatures of SAR signals to target properties (Ulaby et. al., 1987; Boerner et. al., 1987; Wang and Mo, 1990). These studies indicate that the relative phase angles of polarized SAR signals are dependent on the physical, dielectric and geometrical properties of targets and distribution of polarization phase over natural distributed targets provide useful information about target properties. It is of great significance tropical Asia where rice (Oryza sativa L.) is the main crop. The use of SAR images for the assessment of rice-planted area has already reached to operational stage in Asian countries owing to its characteristic temporal signature. However, applications of SAR images for the estimation of biophysical plant variables are challenging, especially for understanding crop scattering mechanisms and discrimination. Canopy geometry and architecture mainly govern the interaction of microwave signal with the vegetation. Previous studies based on ground-based scatterometer have shown potential but detail studies for operational scale is lacking. In this study evaluation of C-band SAR data at different polarization combinations in linear as well as circular polarimetric imaging modes for major crops and other associated landuse has been attempted with the following objectives.

\section{OBJECTIVES}

1) To understand the response of SAR data for crops other than paddy. 
2) To relate SAR response at various polarizations (linear and circular) to canopy structure and geometry.

3) To understand the scattering response as manifested by various biophysical parameters for different crops.

\section{STUDY AREA AND DATASETS}

\subsection{Study area:}

Three sites representing north, west and eastern parts of India were studied.

1) N. India: Central State Farm located in Hisar district of Haryana (India) lies between the coordinates $29^{\circ} 11^{\prime}$ $29^{\circ} 20^{\prime} \mathrm{N}$ latitudes and $75^{\circ} 36^{\prime}-75^{\circ} 45^{\prime} \mathrm{E}$ longitudes was one of the study area. This is a farmland of considerable size where large experimental crop fields are maintained for seed generation and distribution to the state farmers. The major agricultural crops grown in this area include paddy, cotton and pulses during Indian kharif (summer/monsoon) season and wheat, mustard, gram, peas during Indian rabi (winter) season. Some of the field photographs are shown in fig. 2. This site was selected for developing methodology for crop discrimination and classification using polarimetric SAR data from Radarsat-2. Samples were collected from other wheat districts including Hisar, Fatehabad, Jind, Kurukshetra, Kaithal, Karnal and Ambala for biomass/ biophysical parameters collection.

2) West India: Part of Gujrat including Mehesana and Ahmedabad districts were selected for the study. The area lies between the coordinates $21^{\circ} 15^{\prime}-23^{\circ} 15^{\prime} \mathrm{N}$ latitudes and $70^{\circ} 00^{\prime}-72^{\circ} 45^{\prime} \mathrm{E}$ longitudes. Farmer's fields were visited and biomass and other biophysical parameters were collected. Other soil and plant parameters were studied as listed in the table 2.

3) East India: Part of Murshidabad and Burdwan districts $\left(22^{\circ} 30^{\prime} \mathrm{N}\right.$ and $88^{\circ} 30^{\prime} \mathrm{E}$ ) of West Bengal were studied. The major crops in this area in kharif season are monsoon paddy and Jute. Jute is an important fibre crop in south - east Asia and its economic part being phloem bast, better correlation of plant height to backscatter was observed in comparison to total above ground biomass to backscatter, thus plant height in subsequent years were sampled.
3.2. Datasets: Monsoon season is prolonged in India from June to September and incurs unavailability of cloud free optical data for crop monitoring. Thus active microwave data was resorted to for detailed analysis. Multi-date, C-band single-look complex (SLC) data have been used for this study (Table 1). In SLC data, each resolution cell of the image, called pixel is characterized by amplitude value and absolute phase value both are jointly represented as a 'complex number'. All the seven scenes were acquired between July 2010 and March 2011 coinciding kharif and rabi cropping seasons with wheat, mustard, gram as predominant rabi crops and paddy, cotton, guar as predominant kharif crops. In addition RISAT-1 systematic MRS descending pass data during November 2012/13- March 2013/14, July 2013-September 2013 were also studied for crop biophysical parameters studies. Apart from the satellite data, rainfall data during the cropped season, detailed ground data for both plant and soil parameters (table 2) were collected for all the crops.

\section{METHODOLOGY:}

4.1 Analysis approach: Preprocessing of SAR data has been carried out by the standard procedures which included data import, filtering, calibration, georeferencing, multidate co-registration, digital analysis and classification of rice areas (Fig 1). Approach includes overlaying of the GPS points on the multidate coregistered image and subsequent extraction of the crop pixels by elimination of the non- agricultural areas like urban, water body, fallow land, forests and other vegetation with the help of region specific hierarchical decision rule. The GPS co-ordinates of the crop of interest were marked as polygons and used for signature/ backscatter value extraction. Polygons outside these denote the controlled rice patches.

\subsection{Biophysical parameter study}

Multitemporal Radarsat 2/ RISAT-1 Synthetic Aperture Radar ScanSAR/MRS data has been used for the retrieval of biomass and biophysical parameters- canopy cover, plant height, plant density and others (table 2). The details of the methodology are summarized in the flow sheet (fig 1).

Table 1: Details of Radarsat-2 and RISAT-1 data used in this study

\begin{tabular}{|c|c|c|c|c|c|}
\hline $\begin{array}{l}\text { Sl. } \\
\text { No. }\end{array}$ & Polarization & $\begin{array}{l}\text { Central } \\
\text { Inc. } \\
\text { Angle }\end{array}$ & $\begin{array}{l}\text { Acquisition Mode } \\
\text { and beam }\end{array}$ & $\begin{array}{l}\text { Ground Range } \\
\text { Pixel spacing }\end{array}$ & Date of Acquisition: $\mathrm{dd} / \mathrm{mm} / \mathrm{yyyy}$ \\
\hline \multicolumn{6}{|c|}{ Radarsat-2 } \\
\hline 1 & Full: HH,HV,VH,VV & $40^{\circ}$ & $\begin{array}{l}\text { Descending, right } \\
\text { looking FQ21 }\end{array}$ & $6 \mathrm{~m}$ & $\begin{array}{c}\text { 04/07/2010, } 21 / 08 / 2010,08 / 10 / 2010, \\
24 / 12 / 2010, \text {, } 7 / 01 / 2011,06 / 03 / 2011, \\
31 / 03 / 2011\end{array}$ \\
\hline \multicolumn{6}{|c|}{ RISAT-1 } \\
\hline 1 & Dual HH/HV & $36-37^{\circ}$ & $\begin{array}{l}\text { Descending, right } \\
\text { looking }\end{array}$ & $18 \mathrm{~m}$ & $\begin{array}{l}\text { 28/11/2012, 23/12/2012, 02/04/2013, } \\
\text { 19/10/2013, 13/11/2013, 02/01/2014, }\end{array}$ \\
\hline
\end{tabular}




\begin{tabular}{|c|c|c|c|c|c|}
\hline & & & & & $\begin{array}{c}15 / 01 / 2014,27 / 01 / 2014,09 / 02 / 2014, \\
21 / 02 / 2014 .\end{array}$ \\
\hline
\end{tabular}

Table 2. Plant and Soil parameters used for the study

\begin{tabular}{|c|c|}
\hline Plant Parameters & Soil Parameters \\
\hline Crop Type & Soil Moisture \\
\hline Sowing Date & Moist soil \\
\hline Plant Density & $\begin{array}{c}\text { Dry Weight of the } \\
\text { Soil }\end{array}$ \\
\hline Number of Branches & Roughness \\
\hline Number of Leaves & \\
\hline Crop Stage & \\
\hline Plant Height (cm) & \\
\hline $\begin{array}{c}\text { Canopy Cover }(\%) \\
\text { Plant above ground } \\
\text { Biomass }\end{array}$ & \\
\hline
\end{tabular}

\subsection{Biomass retrieval:}

Ground truth campaign for green / wet biomass of various crops was carried out to encompass all ranges of biomass values ranging from very low $\left(0.5 \mathrm{~kg} \mathrm{~m}^{-2}\right)$ to very high $\left(10 \mathrm{~kg} \mathrm{~m}^{-2}\right)$ under most of the growing conditions. Relation between fresh biomass to backscatter was explored by an inversion of radiative transfer

\section{RESULTS AND DISCUSSION:}

The research findings of the study are discussed in this section. Though discrimination among various crops were carried out using SAR data in the monsoon season and optical datasets in the post monsoon winter season but attempt using SAR data at various frequencies in both the seasons were carried out to investigate the role of multiparametric SAR data in crop structure/architecture and moisture based studies (Ferrazoli et al., 1997, Haldar et al. 2012, 2014b).

\subsection{Discrimination among major crops and Polarization:}

Full-polarimetric Radar data contains all the scattering information for any polarization state, hence data of any combination of transmit and receive polarizations can be synthesized from full-polarimetric data. Circular polarimetry was simulated from Radarsat -2 full-polarimetric data of Dec, 2010 - function (Fig.1). The inverse relation of biomass with backscatter was used to retrieve biomass under a suitable region. Decision based model (Panigrahy et al. 1997, Chakraborty et al. 2005) was used to take into account all the rice areas. Optimization of the models was done to minimize omission and commission errors of cropped area. More emphasis was laid to avoid commission error by using a conservative rice classification model (Panigrahy et al., 1997) in the present study. The representative model comprising three date imageries used for retrieval of paddy biomass is illustrated in Haldar et al., 2014 b.

As soil backscatter plays dominant role near the harvesting stage in all crops irrespective of their signatures in the phase from early vegetative to panicle ripening till maturity, a cutoff was laid while inverting to take account of the soil/ crop backscatter when the canopy starts drying up. Biomass was estimated at flooded fields or smooth fields with soil moisture near field capacity and the model was re-run for varying soil moisture content. The radiative transfer model based inversion of biomass from backscatter was direct for the first rising portion of the curve. From this, we retrieve the mean biomass; mean transplantation /sowing date and corresponding frequency for all the series of transplantation in 5 days interval. This information was used for fitting growth curve. The sigmoid growth curve was fitted using Monte-Carlo simulation with least square error. From the fitted curve we derive scattering and geometrical parameters (table 1), the peak age, peak biomass, corresponding age of the crop and the inflection points have also been derived for rice crop (Shao et al., 2001, Chakraborty et al., 2005 and Haldar et al., 2014 b).

Mar, 2011 at every 24 days interval for the central state farm at Hisar, Haryana (India). Linear dual polarized (HH/HV and $\mathrm{VV} / \mathrm{VH}$ ) data vis a vis circular dual polarized (RR/RL) data was conjunctively studied for the separability of various crop types. VV polarized data in conjuction with HV polarized data were sufficient to discriminate between the planofiles (mustard and cotton) and erectophiles (paddy and wheat) at early to mid -vegetative stage till when the growth of the erectophile is completely in vertical direction (Macelloni et al., 2001). VV polarized signal gets significantly attenuated by the erectophile crops as compared to the planophiles in comparison to $\mathrm{HH}$ polarized signal. Significant attenuation occurs for planofiles and erectophile crops in $\mathrm{VV}$ polarization, the fundamental architecture of both being vertical in larger part of the phenology. Thus VV/HV polarization stands out to be better discriminator for wheat and mustard as compared to $\mathrm{HH} / \mathrm{HV}$. 


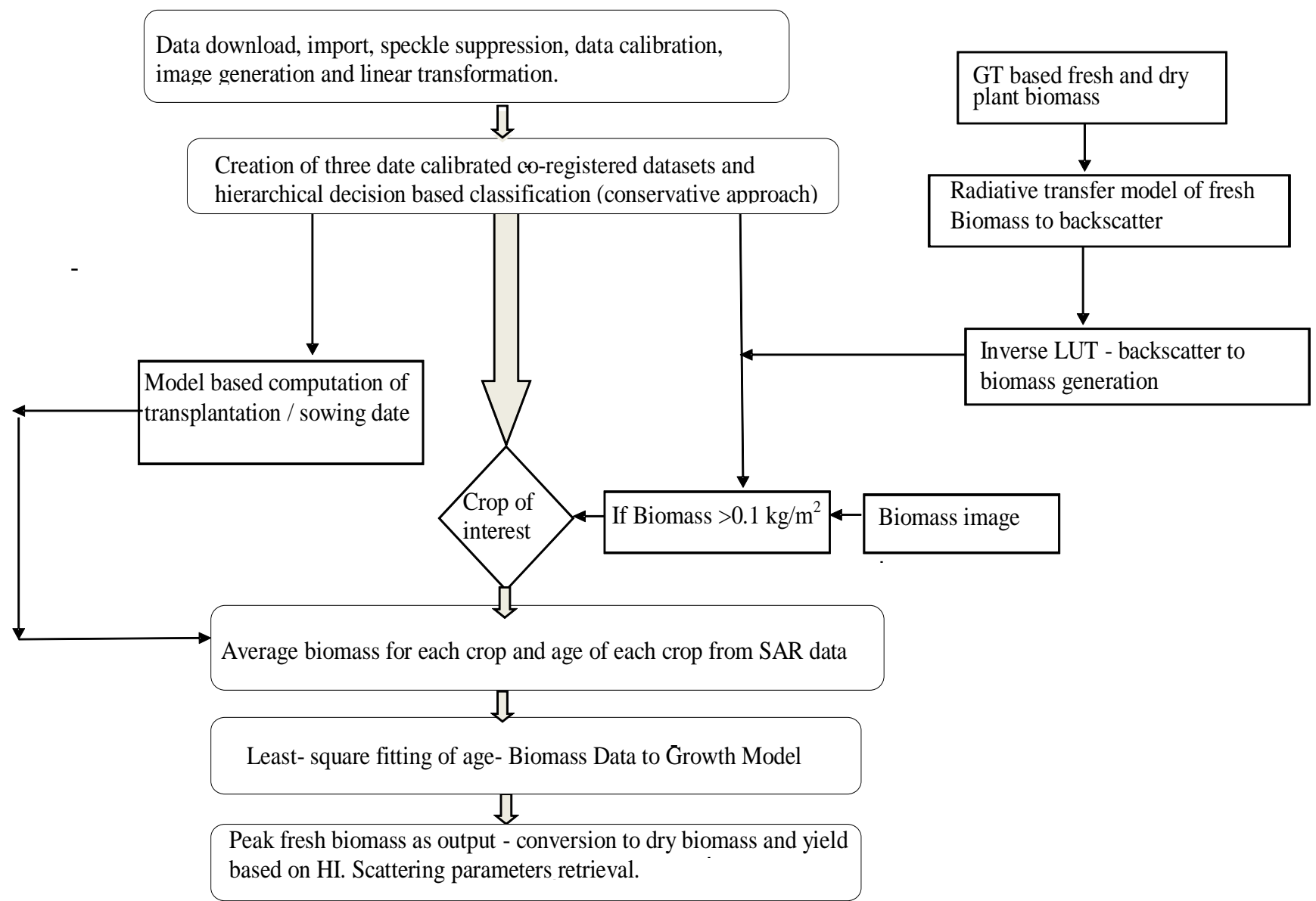

Fig.1 Flow-diagram for data analysis and retrieval of biophysical parameters.

The highest discrimination are observed for circular cross polarized ratio at $\mathrm{C}$ band through a strech of 8 units in comparison to 5 units in case of linear cross-polarized ratio. This result finds explanation due to presence of large leaves in crops with low plant density as in case of mustard and cotton. Large leaves generate, particularly at high frequencies, a "facet" scattering, whose properties are similar to those attributed to surface scattering in the literature (Bouman, 1991, Sarabandi et al., 1992b). Depolarization effects lower than those produced by inclined stems, high correlation between $\mathrm{VV}$ and $\mathrm{HH}$ channels for planophiles (Macelloni et al., 2001). These polarimetric properties generate a good discrimination. Circular dual polarized (RR) signal like HV polarization captures the volume scattering information and aids in the crop discrimination. Circular cross polarized ratio $\mathrm{RR} / \mathrm{RL}$ shows greater temporal increase for the planophiles (4-6 $\mathrm{dB})$ as compared to the erectophiles (1-1.5 dB) as observed in Dec to April crop calendar. Combined use of RR/RL and $\mathrm{HH} / \mathrm{HV}$ polarization increased the accuracy of crop discrimination by 10 $\%$. This is in line with confirmation to the findings of Jiao et al., 2011.

The ground observed biomass and plant height showed decreasing trend with backscatter for wheat more significantly in $\mathrm{VV}$ (than $\mathrm{HH}$ or HV) and increasing trend for mustard, more so in $\mathrm{HV}$ than $\mathrm{HH}$ or VV polarization.
4.2. Canopy structure and interaction: Biomass variation is studied in relation to backscatter for planophiles and erectophiles. Planophiles like mustard showed a positive relation with backscatter while erectophiles may show a positive, negative or constant relation depending on interplay between soil and canopy response to total backscatter. The scattering parameters $(\alpha, \Omega)$, attenuation parameter and geometric parameter $(G)$ were found indicative of the canopy structure and all three vary through the different crops - paddy, wheat, cotton and mustard as observed through the fitting exercise (table 3). The varied response of different polarization to the crop structure and geometry leads to the different mechanism of interaction of the plant component with the incident polarized signal (Fig.3).

The two important rabi crops in this region are mustard and wheat- the former is sown during end September- early October, being planophile in nature covers the soil with faster growth rate within 4-5 weeks of sowing. Mustard is sown after harvest of paddy hence ahead of wheat which is sown post harvest of the cotton in most parts of northern India. Further wheat being an erectoplile has slow growth rate during the initial phase, which results in dominant soil signature in the early and mid season crop stage. Initial high backscatter due to moist rough soil was observed in wheat fields which decreased due to smoothening and drying of soil. The increase in backscatter due to increased biomass due to crop growth was less compared to 
the decrease in backscatter due to smoothening of rough soils with resultant backscatter smaller than initial. This was manifested as decrease in backscatter with biomass or crop age. Macelloni et al., 2001 also reported differed observation based on crop architecture specifically broad and narrow leaf crops.

\subsection{Scattering properties of crops:}

The scattering parameters estimated for various crops gives an insight to the mechanism of partitioning of the EM radiation to different sinks viz. scattering, absorption, emission, reflection, refraction etc. The $\Omega$ range $0.5-0.98$ indicated the nature of canopy material whether it is scattering (as observed in case of paddy, mustard, cotton) or absorbing (wheat). The $\Omega$ for broad leaved is higher $(>0.75)$ than narrow leaved $(<0.7)$. It represents the fraction of attenuated energy lost due to scattering alone. The complementary part of the above parameter reflects the loss due to absorption $(\alpha)$ and depolarization of original signal of SAR. The geometrical parameter value ranges between 0.6-0.9 and determine isotropy (mustard and cotton) and anisotropy (wheat and paddy) of scattering.

\subsection{Biomass and backscatter:}

For Cotton, back scatter increased with biomass through out the growth phase. In planophiles, soils get quicky covered and fast increase in canopy covers which dominantly govern initial biomass contribution to back scatter. However logarithmic relation (Fig 4) indicates increase with decreasing rate that can be extrapolated to plateau. The saturation is likely to be near $6 \mathrm{~kg} \mathrm{~m}^{-2}$ for most of the crops at c-band frequency. The highest correlations were observed for parameters sensitive to volume scattering (HV, LL, and RR backscatter, Freeman Durden volume-scattering parameter) by Jiao et al., 2011. For corn and soyabean they reported correlation coefficient in range of 0.8 to 0.9.Earlier study (Chakraborty et al., 2005, Haldar et al., 2014b) has reported saturation effect at C-band at above $5.7 \mathrm{~kg} \mathrm{~m}^{-2}$. In later stage of crop interaction of $\mathrm{C}$-band remains confined to the top layers of canopy layer that shadows the ground /soil part. Any additional change in crop biomass after a certain stage in high biomass crop thus does not get manifested as resultant backscatter. Higher wavelength viz. S and $\mathrm{L}$ band is therefore required for biomass estimation in later stage of crop particularly advanced stage of high biomass crops. Similar is the case with mustard; however rate of increase in backscatter is relatively higher than cotton owing to fast leaf expansion. Extrapolating the trend as previous, attenuation are likely to be round $6 \mathrm{~kg} / \mathrm{m}^{2}$ of biomass at backscatter value around ( -5 to- $\left.6 \mathrm{~dB}\right)$. Jiao et al., 2011 reported loss in sensitivity to LAI was lost late in the season, when the derived LAI exceeded $3.0 \mathrm{~m} 2 / \mathrm{m} 2$. The derived LAI and the measured soil moisture were used to model several radar parameters (HV backscatter, pedestal height, and the Freeman-Durden volume-scattering parameter) using the watercloud model (Jiao et al., 2011) and with other biological variables by Inoue et al., 2002.

For Jute crop, plant height was taken as parameter for study in place of biomass because plant height is more likely to be related to economic biomass at least for initial stage. For height upto about 4 feet, backscatter was in the range of -9 to $-4.7 \mathrm{~dB}$ and increased with plant height. The saturation effect was realized just beyond this range in the early to medium stage but logarithmic relation indicates decreasing rate of increase in backscatter with plant height upto 4 feet. Also as is apparent from the backscatter value after $-4.7 \mathrm{~dB}$, practically no scope of retrieval remains. Saturation is highly likely before realizing full height $(>200 \mathrm{~cm})$, biomass $\left(>8 \mathrm{~kg} / \mathrm{m}^{2}\right)$ which converts to economic yield. The trend of backscatter (Fig. 3) for erectophiles (wheat) was observed to be reverse as compared to those of planophiles (cotton, mustard). Wheat is sown in clean tilled moist soil that lead to very high initial backscatter (-9db). Backscatter sharply decreased with drying and smoothening of soil. Subsequent increase in biomass was not high enough to match the total backscatter from canopy and soil unlike most of the planophiles. Up to biomass of $4.5 \mathrm{~kg} / \mathrm{m}^{2}$ decreasing trend of backscatter with biomass were visible but low sensitivity was visible thereafter (Fig 4). This work reported saturation at around $5 \mathrm{~kg} / \mathrm{m}^{2}$. However further study sampling with broader range of biomass is required to corroborate the finding and extrapolation under other growing conditions. This is direct implication of variable scattering mechanisms of the various crops. The behavioral pattern for rice is similar to planophiles with monotonic increase leading to a plateau due to water background in the initial phase of growth. The established response of plant architecture in SAR can be used for crop condition assessment and biophysical parameter retrieval. $\mathrm{C}$ band backscatter is though responsive to change in biomass in earlier stage of crops but Lband need to be evaluated for later stage of crops and the same study should be extended through various agricultural regimes.

Table: 3- Scattering parameters for various crops

\begin{tabular}{|c|c|c|c|c|c|}
\hline $\begin{array}{c}\text { Crops } \\
\text { (polarization) }\end{array}$ & $\Omega$ & $\mathrm{G}$ & $\alpha$ & $\mathrm{SE}$ & $\mathrm{R}^{2}$ \\
\hline Paddy(HH) & 0.64 & 0.66 & 0.105 & 0.86 & 0.93 \\
\hline Cotton(HH) & 0.80 & 0.40 & 0.741 & 0.67 & 0.71 \\
\hline Mustard (HH) & 0.77 & 0.56 & 0.797 & 0.49 & 0.82 \\
\hline Mustard (HV) & 0.90 & 0.94 & 0.811 & 0.47 & 0.90 \\
\hline Mustard(VV) & 0.82 & 0.67 & 0.850 & 0.99 & 0.63 \\
\hline Wheat (HH) & 0.701 & 0.80 & 0.290 & 1.19 & 0.45 \\
\hline
\end{tabular}



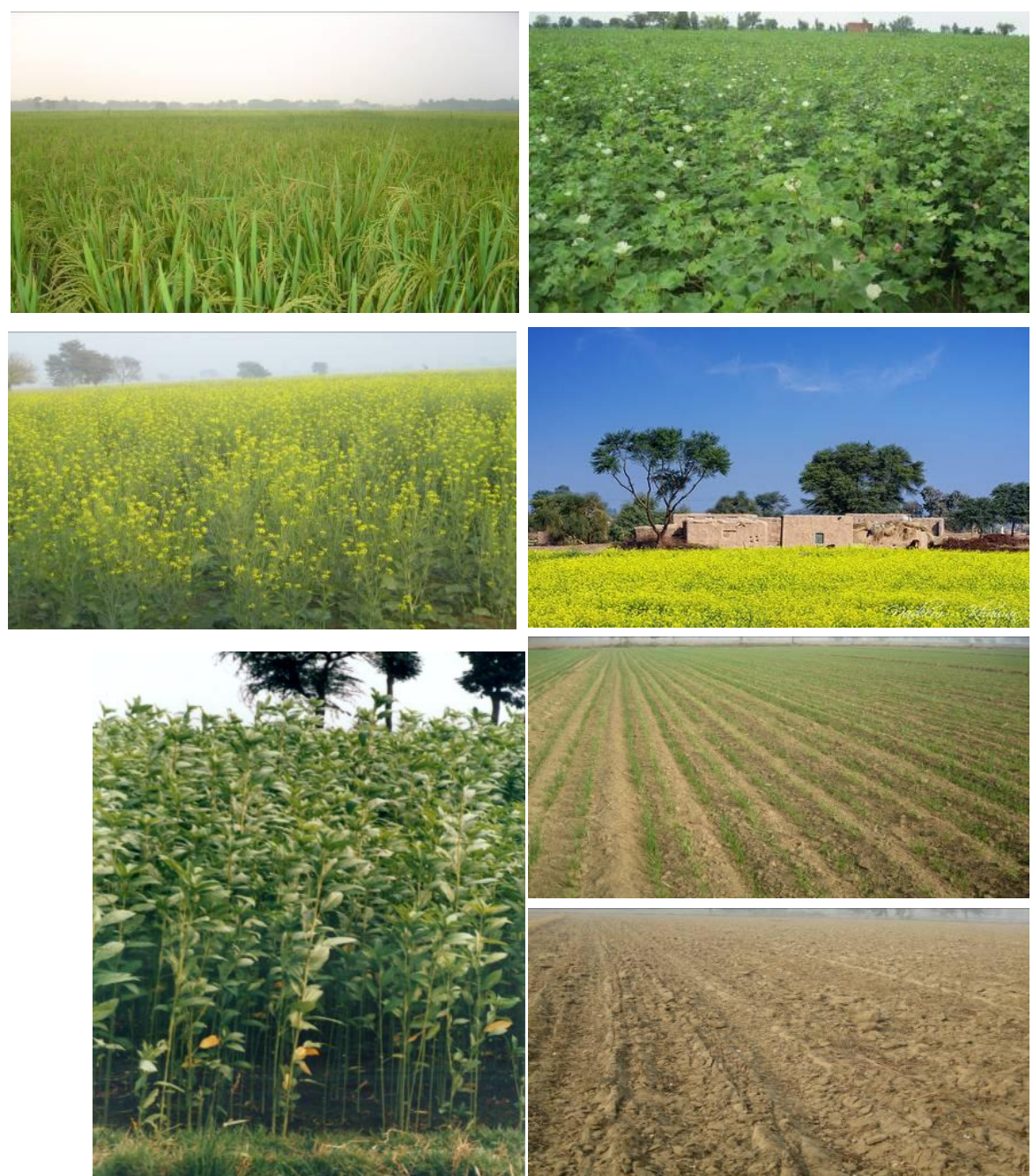

Fig. 2. (a)-(h) Field photographs of various crops of Kharif and Rabi season: (a) paddy crop with panicles.(b) Cotton crop in peak flowering stage (c) Mustard in peak flowering stage (d) rural settlement adjoining the mustard fields (e) wheat in early tillering stage (f) Jute in vegetative stage $(\mathrm{g})$ recent ploughed fallow land prepared for next crop.

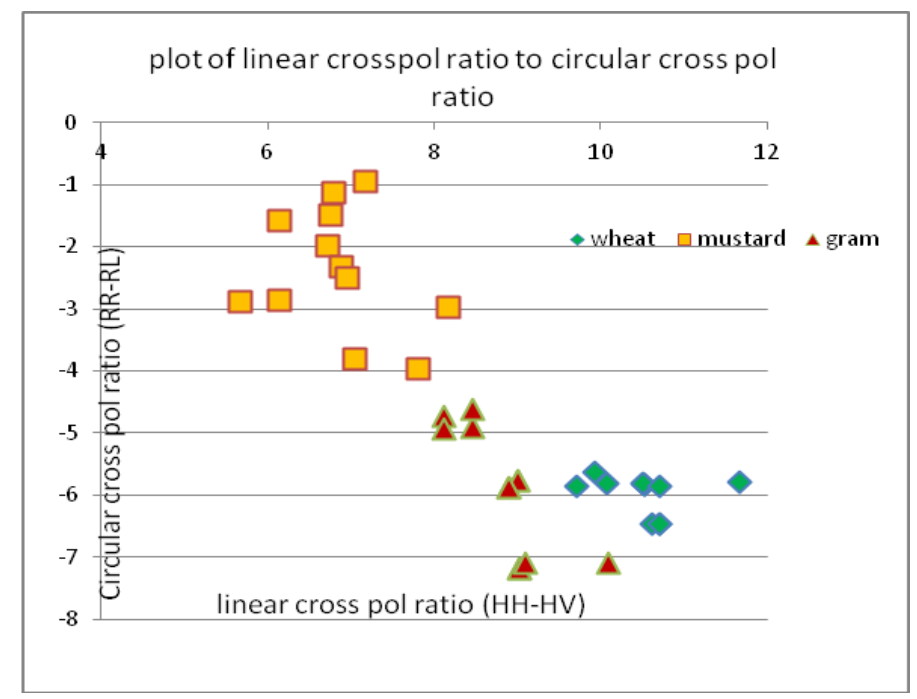

Fig.3. Plot of circular cross polarization ratio vs. linear polarization ratio. 

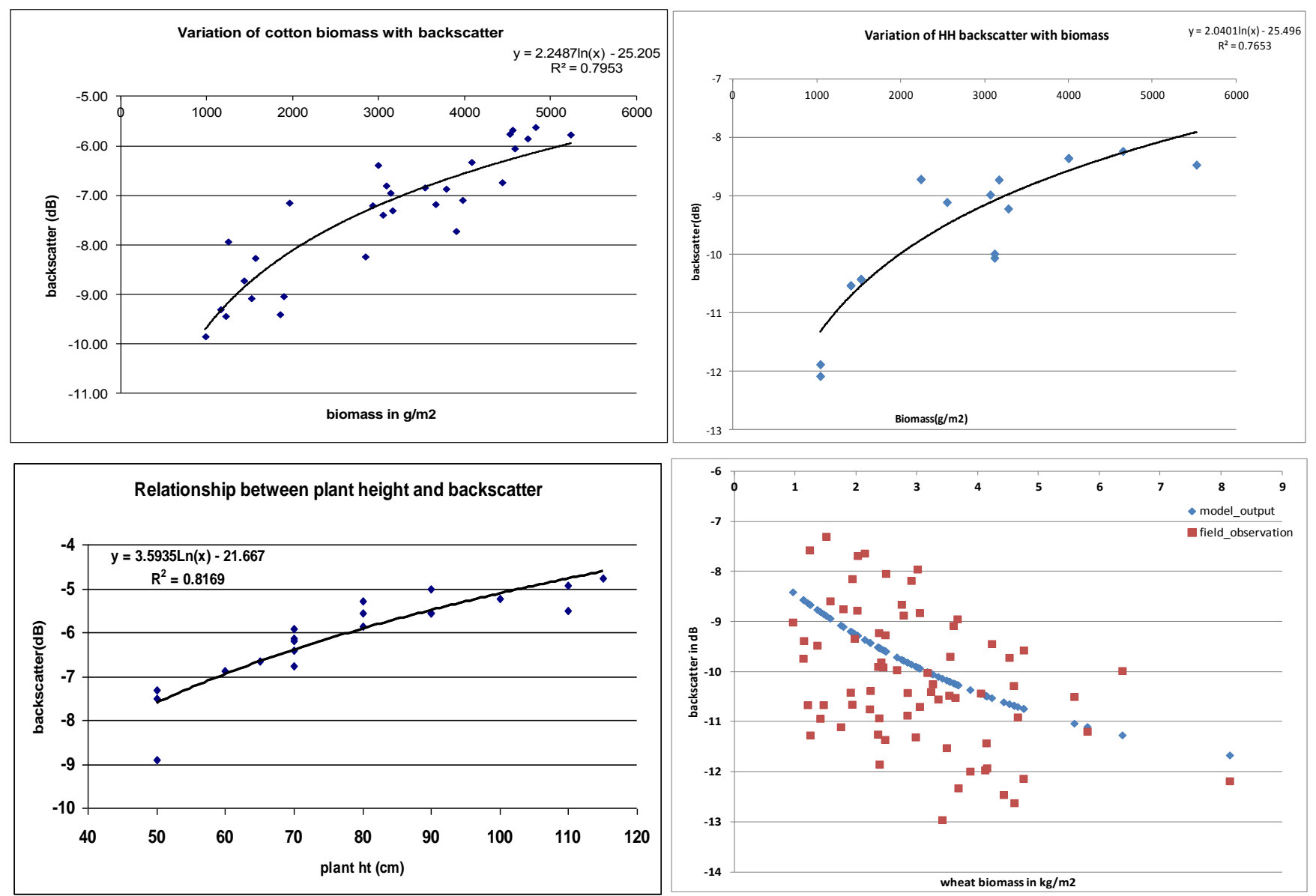

Fig. 4. Relation of biomass with backscatter for broad leaved crops viz. a) cotton and b) mustard and c) for narrow leaved crop eg. c) Jute crop with height measurements d) Wheat with measured biomass samples.

\section{Conclusion}

The study focused on the utility of multi-dimension SAR data for crop condition assessment of various important tropical crops in India. VV/HV polarization stands to be better discriminator for wheat and mustard as compared to $\mathrm{HH} / \mathrm{HV}$. Circular cross polarized ratio added significantly to the discrimination capability. Combined use of RR/RL and HH/HV polarization increased the accuracy of crop discrimination by about $10 \%$. Backscattered value increased with biomass in early to mid crop stage of cotton, mustard and Jute but extrapolation of trend indicates saturation at higher level of biomass in C- band. In case of wheat, decreasing

Ainsworth, T. L., Kelly, J. P. and Lee, J.-S., "Classification comparisons between dual-pol, compact polarimetric and quad-pol SAR imagery," ISPRS Journal of Photogrammetry and Remote Sensing, vol. 64, pp. 464-471, 2009.

Boerner, W.M., Foo, B.Y. and Eom, H.J., "Interpretation of the polarimetric co-polarization phase term in radar images obtained with JPL airborne L-band SAR system", IEEE Transactions on Geosci. and Remote Sensing, vol. GE-25, no. 1, pp. 77-82, 1987.

Bouman, B. A. M. 1991. "Crop Parameter Estimation from Ground-Based X-Band (3-cm Wave) Radar Backscattering Data." Remote Sensing of Environment 37: 193-205. trend of backscatter with relatively low sensitivity was observed at biomass above $5 \mathrm{~kg}$ per square meter in C-band. Thus there is scope of retrieval of the scattering parameters in higher wavelength in advanced crop stage. Probably soil backscattering dominated the trend in case of wheat however sampling with broader biomass range is necessary to corroborate the finding. Our future thrust area would be to take an exercise with other agricultural regime and at lower frequencies which would encompass.

\section{REFERENCES:}

Doraiswamy, P. C., J. L. Hatfield, T. J. Jackson, B. Akhmedov, J. Prueger, and A. Stern. 2004. "Crop Condition and Yield Simulations Using Landsat and MODIS." Remote Sensing of Environment 92: 548-59.

Ferrazzoli P., Paloscia S., Pampaloni P., Schiavon G., Sigismondi S. and Solimini D. The Potential of Multifrequency Polarimetric SAR in Assessing Agricultural and Arboreous Biomass. IEEE Transactions on Geosci. and Remote Sensing, VOL. 35, NO. 1, 1997.

Freeman, A., "Fitting a two component scattering model to polarimetric SAR data from forests" IEEE Transactions on Geosci and Remote Sensing, vol. 45, no.8, pp. 2583-2592, 2007. 
Freeman, J., Villasenor, J. D., Klein, H. P. and Groot, J., "On the use of multi-frequency and polarimetric radar backscatter features for classification of agricultural crops," Int. J. Remote Sensing, vol. 15, no. 9, pp. 1799-1812, 1994.

Haldar, D., Manjunath K. R., Panigrahy S. , Jain V., Gopalan R. S., Khullar, M. , Chakraborty, M. and Parihar J. S. Monsoon paddy monitoring and assessment using synthetic aperture radar data under BGREI programme in Odisha, India. Paddy and Water Environment 2014. http://link.springer.com/article/10.1007/s10333-014-0452-0.

Haldar, D., Das, A., Mohan, S., Pal, O., Hooda, R.S. and Chakraborty, M., "Assessment of L-band SAR data at different polarization combinations for crop and other landuse classification", Prog. In Electromagnetic Research B. (PIER), vol.36, pp. 303-321, 2012.

Hoekman, D. H. and Bouman, B. A. M., "Interpretation of C- and $\mathrm{X}$-band radar images over an agricultural area, the Flevoland test site in the agriscatt-87 campaign," International Journal of Remote Sensing, vol. 14, pp.1577-1594, 1993.

Inoue, Y., T. Kurosu, H. Maeno, S. Uratsuka, T. Kozu, K. Dabrowska-Zielinska, and J. Qi. 2002. "Season-Long Daily Measurements of Multifrequency (Ka, Ku, X, C, and L) and FullPolarization Backscatter Signatures Over Paddy Rice Field and Their Relationship with Biological Variables." Remote Sensing of Environment 81: 194-204.

Jiao X., McNairn H., Shang J, Pattey E, Liu J., and Champagne C. The sensitivity of RADARSAT-2 polarimetric SAR data to corn and soybean leaf area index. Can. J. Remote Sensing, Vol. 37, No. 1, pp. 69-81, 2011.

Kurosu, T., Fujita, M. and Chiba, K., "Monitoring of rice crop growth from space using the ERS-1 C-band SAR," IEEE. Trans. Geosci. Remote Sensing, vol. 33, pp. 1092-1096, July 1995.

Lee, J.-S., M. R. Grunes, and E. Pottier, "Quantitative comparison of classification capability: Fully polarimetric versus dual-and single-polarization SAR," IEEE Transactions on Geosci. and Remote Sensing, vol. 39, no. 11, pp. 2343-2351, 2001.

Macelloni G., Paloscia S., Pampaloni P., The Relationship Between the Backscattering Coefficient and the Biomass of Narrow and Broad Leaf Crops. , IEEE Transactions on Geosci. and Remote Sensing, VOL. 39, NO. 4, 2001

Panigrahy R.K. and A K Mishra. An Unsupervised Classification of scattering behaviour using Hybrid Polarimetry. IET Radar, Sonar \& Navigation, p 270- 276, Vol.7(3), Mar, 2013.

Sarabandi K., Y. Oh, and F.T. Ulaby, "Measurement and Calibration of Differential Mueller Matrix of Distributed Targets," IEEE Trans. Antennas Propagation, vol. 40, pp. 1524-1532, Dec. 1992b.

Schon H., Hajsnek, I., Jagdhuber, T., Papathanassiou K., Microwave and Radar Institute, German Aerospace Centre, DLR. helmut.schoen@dlr.de

Schotten, C. G. J., Van Rooy, W. W. L. and Janssen, L. L. F., "Assessment of the capabilities of multi-temporal ERS-1 SAR data to discriminate between agricultural crops," Int. J. Remote Sensing, vol. 16, no. 14, pp. 2619-2637, 1995.
Shao, Y., X. Fan, H. Liu, J. Xiao, S. Ross, B. Brisco, R. Brown, and G. Staples. 2001. "Rice Monitoring and Production Estimating Using Multitemporal RADARSAT." Remote Sensing of Environment 76: 310-25.

Skriver, H., Morten, T. S. and Thomsen, A. G., "Multitemporal Cand L-band polarimetric signatures of crops," IEEE Transactions on Geosci. and Remote Sensing, vol. 37, no. 5, pp. 2413-2429, 1999.

Toan, L. T., H. Laur, E. Mougin, and A. Lopes, "Multitemporal and dual-polarization observations of agricultural vegetation covers by X-band SAR images," IEEE Trans. Geosci. Remote Sensing, vol. 27, pp. 709-717, Nov. 1989.

Toan, L.T., Ribbes, F., Wang, L. F., Floury, N., Ding, K. H., Kong, J. A., Fujita, M. and Kurosu, T., "Rice crop mapping and monitoring using ERS-1 data based on experiment and modeling results," IEEE Trans. Geosci. Remote Sensing, vol. 35, pp. 41-56, Jan. 1997.

Turkar, V., Deo, R., Rao, Y.S., Mohan, S. and Das, A. "Classification accuracy of multi-frequency and multi-polarization SAR images for various land covers", IEEE Journal of Selected Topics in Applied Earth Observations and Remote Sensing, vol 5, no. 3, pp. 936 - 941, June 2012.

Ulaby F.T., Sarabandi, K. and Nashashibi, A., "Statistical properties of the Muller matrix of distributed Targets", IEE Proceedings- $F$, vol. 139, no. 2, 1992.

Ulaby, F.T., Held, D., Dobson, M.C., McDonald, K.C. and Thomas, B.A., "Relating polarization phase difference (PPD) of SAR signals to scene properties", IEEE Transactions on Geosci. and Remote Sensing, Vol. GE-25, no. 1, pp.83-91, 1987.

Wang, J.R. and Mo T., "The polarization phase difference of orchard trees", International Journal of Remote Sensing, vol. 11, no. 7 , pp. $1255-1265,1990$. 